\title{
Intertrimer and Intratrimer Metallophilic and Excimeric Bonding in the Ground and Phosphorescent States of Trinuclear Coinage Metal Pyrazolates: A Computational Study
}

\author{
Tom Grimes,${ }^{\dagger}$ Mohammad A. Omary, ${ }^{\dagger}$ H. V. Rasika Dias,,${ }^{\dagger}$ and Thomas R. Cundari $*, \dagger$ \\ Department of Chemistry and Center for Advanced Scientific Computing and Modeling (CASCaM), University \\ of North Texas, P.O. Box 305070, Denton, Texas 76203-5070, and Department of Chemistry and Biochemistry, \\ The University of Texas at Arlington, Arlington, Texas 76019
}

Received: January 24, 2006

\begin{abstract}
The interactions present in cyclic trinuclear coinage metal pyrazolates were studied computationally. Cuprophilic interaction was found to bind the singlet ground state of the dimer of trimers $\left\{[\mathrm{Cu}(\mathrm{Pz})]_{3}\right\}_{2}$, overcoming electrostatic repulsion. The large variation in intertrimer separations found in the literature for coinage metal pyrazolates is consistent with the relatively weak metallophilic interaction. The emissive triplet excited-state geometry of $\left\{[\mathrm{M}(\mathrm{Pz})]_{3}\right\}_{2}$ is predicted by density functional calculations to show major geometric distortion caused by Jahn-Teller instability and excimeric $\mathrm{M}-\mathrm{M}$ bonding. Large calculated Stokes' shifts, which are also observed for experimental models, are consistent with significant excited-state distortions for these materials. The major finding derived from the present study is that the intertrimer $\mathrm{M} \cdots \mathrm{M}$ contraction in the emissive $T_{1}$ state is much more than the intratrimer contraction in all $\left\{[\mathrm{M}(\mathrm{Pz})]_{3}\right\}_{2}$ models, giving rise to a lower $\mathrm{T}_{1} \rightarrow \mathrm{S}_{0}$ phosphorescence energy in these models than in analogous monomer-of-trimer models. The observations made here point to a great potential for rationally tuning the emission properties of trinuclear coinage metal complexes through choice of the metal and ligands.
\end{abstract}

\section{Introduction}

Coinage metal cyclic pyrazolate trimers (Chart 1) form supramolecular assemblies with differing degrees of intertrimer and intratrimer metal-metal bonding, resulting in interesting chemical and photophysical properties. There are many influences on the interactions between the trimers, and indeed, Omary, Dias, and co-workers have shown that the emission energies and unit cell dimensions of these materials have significant changes with temperature, leading to startling luminescence thermochromism. ${ }^{1,2}$ Many possibilities exist for modes of intertrimer interactions, leading to supramolecular structures, including extended linear and zigzag chains and dimers of trimers in which adjacent trimers are packed in various conformations that include chair, prismatic, star-shaped, stepladder, etc., ${ }^{1-4}$ akin to those known for cyclic trinuclear coinage metal trimers of other bridging ligands besides pyrazolates. ${ }^{5}$ The bridging-ligand substituents and the coinage metal also determine the balance between acid/base behavior, electrostatic interactions, metallophilicity between $\mathrm{d}^{10}$-metal pairs, and the luminescence behavior. ${ }^{1-6}$ For example, the parent $[\mathrm{Au}(\mathrm{Pz})]_{3}$ is a basic complex, like most other $\mathrm{Au}^{\mathrm{I}}$ cyclic trimers, ${ }^{5,6}$ whereas addition of trifluoromethyl substituents to the pyrazolate rings yields a trimer that is acidic enough to form a binary adduct with toluene. ${ }^{1}$ The theoretical origin of metallophilicity, which describes $\mathrm{d}^{10}$ metal-metal interactions, has been explored by Pyykkö, ${ }^{7,8}$ Hoffmann, ${ }^{9}$ and others, ${ }^{10,11}$ who related these closedshell interaction ${ }^{5}$ to correlation effects strengthened by relativistic effects ${ }^{7,8}$ or to hybridization of $n$ d orbitals with $(n+1) \mathrm{s}$ and $(n+1)$ p orbitals. ${ }^{9}$ In the cyclotrimeric compounds treated herein, metallophilicity is expected to play an especially

* To whom correspondence should be addressed. E-mail: tomc@unt.edu.

$\doteqdot$ University of North Texas.

$\doteqdot$ The University of Texas at Arlington.
CHART 1: Structure of $\left[M\left(3-(R), 5-\left(\mathbf{R}^{\prime}\right) P z\right)\right]_{3}$ Cyclic Trimers

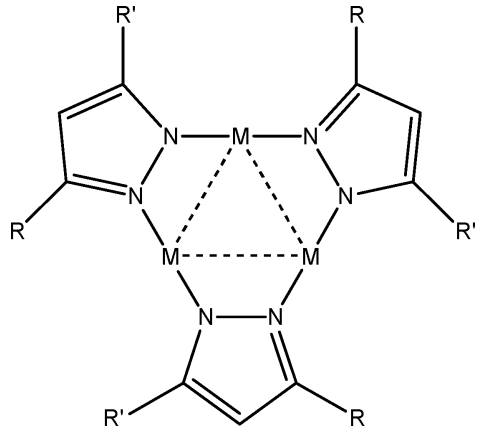

important role because of the large number of close $\mathrm{M} \cdots \mathrm{M}$ pairs. Poblet and Bénard attempted to model similar systems in 1998, but they deemed that "a conclusive argument proving the existence of metallophilic interactions on such large systems is at present impossible to obtain from quantum chemical calculations". ${ }^{11}$ Here, we show that this is now possible for $\left\{[\mathrm{M}(\mathrm{Pz})]_{3}\right\}_{2}$ coinage-metal dimers of trimers and even substituted systems, such as $\left\{\left[\mathrm{M}\left(3-\left(\mathrm{CF}_{3}\right) \mathrm{Pz}\right)\right]_{3}\right\}_{2}$, allowing direct comparison to experiment. This is so not only for the ground-state metallophilic bonding but also for excited-state excimeric $\mathrm{M}-\mathrm{M}$ bonding, which is now accessible experimentally by time-resolved singlecrystal X-ray diffraction for these systems, as demonstrated in a recent elegant study by Coppens and co-workers. ${ }^{12}$

One important aspect of the present study is modeling the photophysics of coinage-metal pyrazolate trimers, which are known to exhibit bright, tunable phosphorescence. The fascinating luminescence properties of these systems found experimentally include drastic sensitivities of the phosphorescence colors and lifetimes to solvent, temperature, concentration, rigidity of medium, substituents on the pyrazolate ring, and identity of the 
coinage metal. ${ }^{1,2}$ Thus, we are able to calculate the theoretical values for the phosphorescence and excitation energies as well as the consequent Stokes' shifts representing the difference between the $\mathrm{T}_{1} \rightarrow \mathrm{S}_{0}$ and $\mathrm{S}_{0} \rightarrow \mathrm{T}_{1}$ vertical transition energies for various monomer-of-trimer and dimer-of-trimer models. The interaction potential energy curve with respect to separation between the pyrazolate trimers is expected to be quite soft. We searched the Cambridge Structural Database ${ }^{13}$ and found a much larger variation in intertrimer versus intratrimer $\mathbf{M} \cdots \mathbf{M}$ distances for coinage metal pyrazolate trimers. An understanding of the nature of the bonding and photophysical properties for coinage metal trimers is necessary to explain how the luminescence properties of these compounds can be tuned and perhaps use this predictive information to rationally design new synthetic targets.

This paper presents computational evidence of a significant change in the geometry of the emissive excited state of coinagemetal pyrazolate trimers. The intermolecular interactions of coinage metal pyrazolate trimers are modeled in dimeric models as a first approximation to the structure in the solid state and even in solution, since these systems exhibit non-Beer's law behavior due to association. ${ }^{1}$ We address how the M $\cdots \mathrm{M}$ metallophilic and $\mathrm{M}-\mathrm{M}$ excimeric interactions change in the ground and phosphorescent excited states of both $[\mathrm{M}(\mathrm{Pz})]_{3}$ monomer-of-trimer and $\left\{[\mathrm{M}(\mathrm{Pz})]_{3}\right\}_{2}$ dimer-of-trimer models. The roles of the coinage metal and the pyrazolate substituents are also assessed in terms of both the geometry of the $S_{0}$ and $\mathrm{T}_{1}$ states as well as the photophysical parameters. We also assess the relative role of metallophilic bonding versus electrostatic attraction in describing the intermolecular interactions between adjacent monomer-of-trimer units.

\section{Computational Methodology}

Methods and Basis Sets. All of the geometry optimizations in this paper were performed at the B3LYP/CSDZ* level in Jaguar. ${ }^{14}$ This method gave bond lengths and energies comparable to those obtained with $\mathrm{B} 3 \mathrm{LYP} / \mathrm{LACV} 3 \mathrm{P}^{* *}++$ on the $[\mathrm{Cu}-$ $(\mathrm{Pz})]_{3}$ singlet and triplet structures, so the computationally less expensive B3LYP/CSDZ* method was chosen for all subsequent calculations in this paper. The CSDZ* basis is the StevensCundari effective core potential $(\mathrm{ECP})^{15}$ for elements heavier than argon; carbon, nitrogen and hydrogen are described by the 6-31G* basis set. For calculation of cuprophilicity, we utilized an approach inspired by Pyykkö; ${ }^{8}$ thus, LMP2 (localized 2ndorder Møller-Plesset perturbation theory $\left.{ }^{16}\right) / \mathrm{CSDZ}^{*}$ and ROHF (restricted open-shell Hartree-Fock)/CSDZ* single-point calculations were run at the B3LYP/CSDZ*-optimized geometries of both singlet and triplet $\left\{[\mathrm{Cu}(\mathrm{Pz})]_{3}\right\}_{2}$. In addition, the counterpoise method ${ }^{17}$ was used to eliminate basis set superposition error (BSSE).

Derivation of Intertrimer Metrics. It was determined that the important interactions in the $\left\{[\mathrm{M}(\mathrm{Pz})]_{3}\right\}_{2}$ dimer-of-trimer systems are between the $\mathrm{M}_{3}$ triangular metal cores; therefore, a set of geometrical parameters defining the pertinent metrics of adjacent $\mathrm{M}_{3}$ units was devised. Each $\mathrm{M}_{3}$ triangle was used to define a plane and a centroid. The direct distance between the centroids was one metric used to quantify the extent of intertrimer interaction (Figure 1a). Also used were the perpendicular separation of the planes (Figure 1b) and the horizontal misalignment of the centroids (Figure 1c). Essentially, the latter two measures are the orthogonal projections of a vector from one centroid to the other, perpendicular to the planes and in the planes, respectively. Since in all cases the two trimers remained parallel, there was no ambiguity in selecting which plane to use as the reference. Furthermore, the angle of rotation

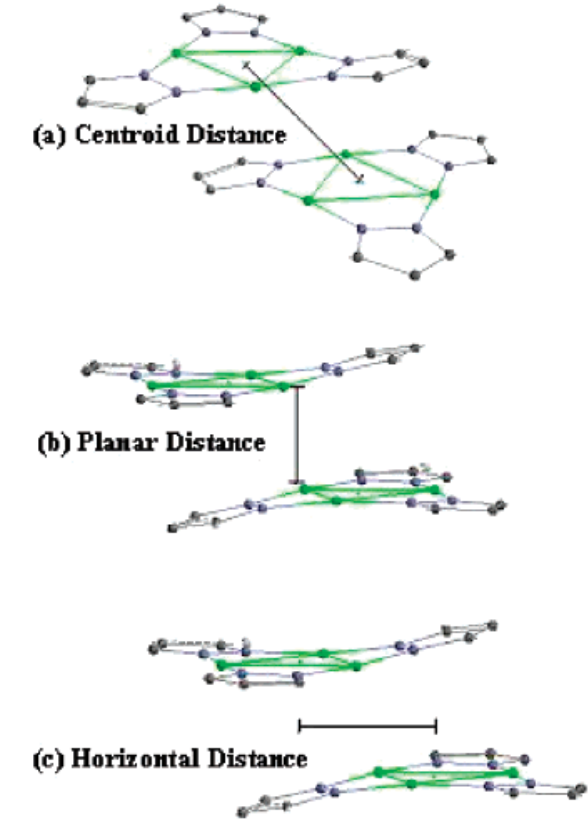

(d) Rotational Angle

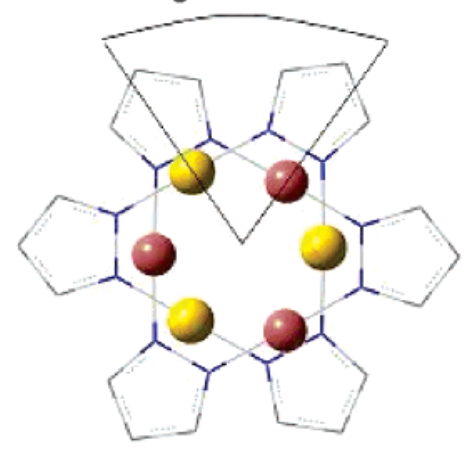

Figure 1. Metrics used to quantify interactions in $\left\{[\mathrm{M}(\mathrm{Pz})]_{3}\right\}_{2}$ dimers of trimers.

between two trimers (Figure 1d) was defined as the angle between the two centroid-vertex vectors as if they existed in the same plane and had the same origin. There is some ambiguity in the rotational angle, since the metal cores did not always form equilateral triangles, but the deviation of the measured angle with the choice of centroid-vertex pair was small.

\section{Results and Discussion}

Cuprophilicity in the $S_{0}$ Ground State of $\left\{[\mathrm{Cu}(\mathrm{Pz})]_{3}\right\}_{2}$. Metallophilicity is an attractive interaction between a pair of $\mathrm{d}^{10}$ atoms that is a result of long-range dispersion forces., ${ }^{7-11}$ There has been some debate regarding the role of cuprophilicity versus electrostatic interaction and ligand assistance in binding $\mathrm{Cu}^{\mathrm{I}}$ dimers in general, ${ }^{10,11}$ although the specific case of intertrimer interactions in trinuclear $\mathrm{Cu}^{\mathrm{I}}$ pyrazolates was suspected to be due to a genuine cuprophilic interaction. ${ }^{2 b, 11}$ With multiple $\mathrm{d}^{10}$ atoms in close contact, metallophilicity may reasonably be expected to play an important role in understanding the dimer-of-trimers interactions in the singlet ground state of $\left\{[\mathrm{Cu}(\mathrm{Pz})]_{3}\right\}_{2}$. Because metallophilicity is widely attributed to dynamic electron correlation, ${ }^{7,8}$ it should be possible to separate cuprophilicity from electrostatic interactions by comparing the dimerization potential of the dimer-of-trimers calculated at the Hartree-Fock level with the potential using a 

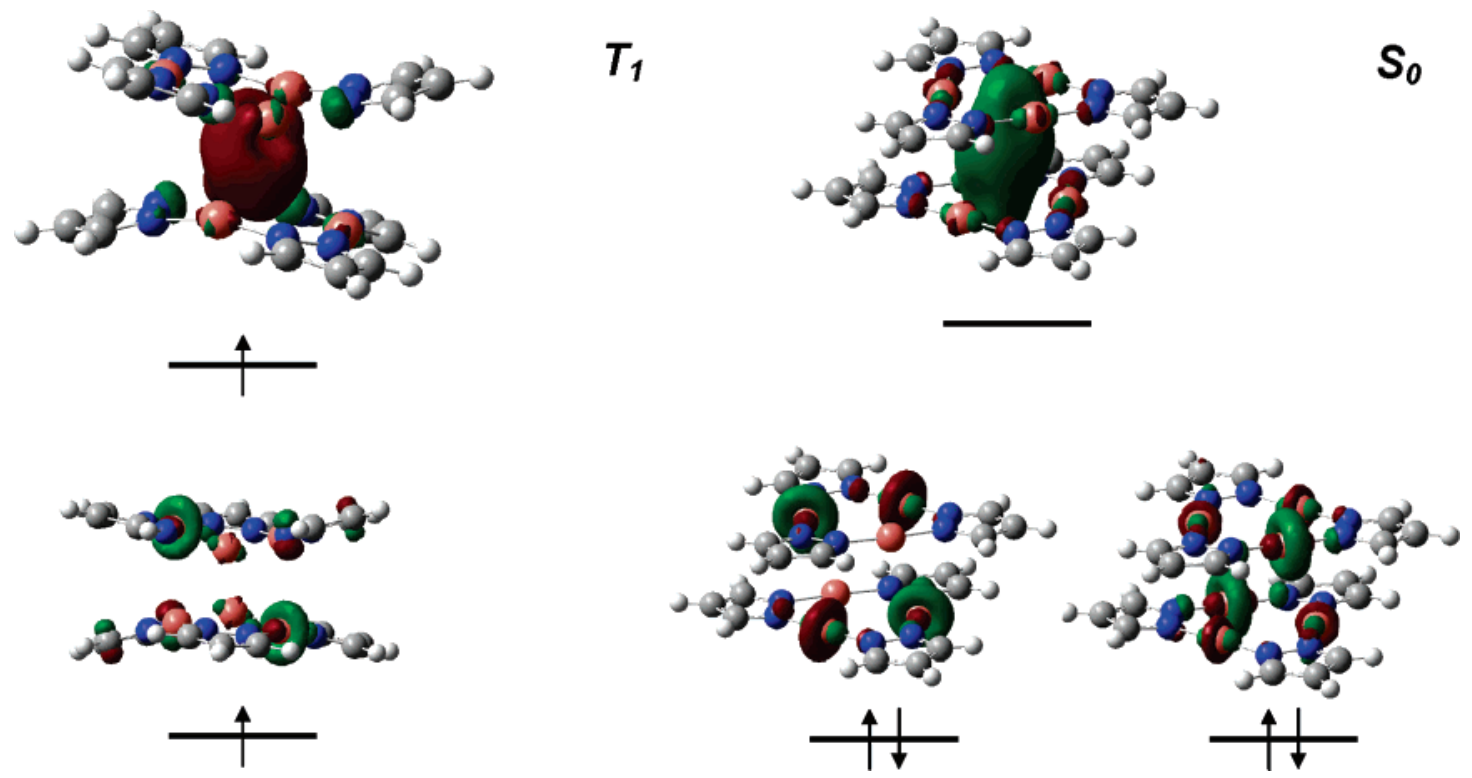

Figure 2. Contours of the frontier orbitals for the optimized $S_{0}$ and $T_{1}$ states of $\left\{[\mathrm{Cu}(\mathrm{Pz})]_{3}\right\}_{2}$.

correlated method (e.g., LMP2). A similar procedure was used by Pyykkö to investigate the attraction of $\mathrm{Au}^{\mathrm{I}}$ ions in linear complexes. ${ }^{8}$ The basis set superposition error $\left(\mathrm{BSSE}^{17}\right)$ for the dimer of trimers is expected to be relatively large when calculating the dimerization energy, so the appropriate counterpoise calculations were performed to correct for this. Since LMP2 is designed to minimize BSSE and the counterpoise correction used with LMP2 has been found to overestimate BSSE, ${ }^{18}$ we applied the counterpoise correction only to the HF calculations. The geometries for these single-point calculations came from optimization at the B3LYP/CSDZ* level.

Here, we present our computational results to analyze cuprophilicity in the $\left\{[\mathrm{Cu}(\mathrm{Pz})]_{3}\right\}_{2}$ dimer of trimer, which models experimental systems that have led to short intertrimer $\mathrm{Cu} \cdots$ $\mathrm{Cu}$ contacts according to the available crystallographic data. For example, $\left[\left(3,5-(\mathrm{Me})_{2} \mathrm{Pz}\right) \mathrm{Cu}\right]_{3},{ }^{2 \mathrm{~b}, 19}\left[\left(3,5-(i-\mathrm{Pr})_{2} \mathrm{Pz}\right) \mathrm{Cu}\right]_{3},{ }^{2 \mathrm{~b}, 20}$ and $[(2-(3-\mathrm{Pz}) \mathrm{Py}) \mathrm{Cu}]_{3}{ }^{21}$ have the shortest $\mathrm{Cu} \cdots \mathrm{Cu}$ intertrimer distances, in the range 2.9-3.0 $\AA$. The staggered conformation is the lowest-energy conformer at the level of theory used, although the chair conformation is more common experimentally, likely due to steric and electronic effects associated with the substituents in the experimental $\left\{\left[\mathrm{M}\left(3-(\mathrm{R}), 5-\left(\mathrm{R}^{\prime}\right) \mathrm{Pz}\right)\right]_{3}\right\}_{2}$ systems. ${ }^{2,4,19-21}$ In the case of the unsubstituted staggered dimerof-trimer $\left\{[\mathrm{Cu}(\mathrm{Pz})]_{3}\right\}_{2}$ model, a HF single-point calculation predicts that the model is not intermolecularly bound in the singlet ground state $(\Delta E=+4.6 \mathrm{kcal} / \mathrm{mol})$, giving rise to a net repulsion between the two adjacent trimers. However, the LMP2 calculations imply that cuprophilicity compensates for the repulsion and binds the dimer of trimers $(\Delta E=-13.5 \mathrm{kcal} /$ mol). Since metallophilicity is an electron correlation effect, the difference between ROHF and LMP2 calculated energies, which results from dynamic electron correlation, is assumed to be due to cuprophilicity. Hence, the overall cuprophilic stabilization for this system is $-18.1 \mathrm{kcal} / \mathrm{mol}$. Since the current approach utilizes DFT-optimized geometries (instead of LMP2 optimized geometries) the calculated cuprophilic stabilization of $-18.1 \mathrm{kcal} / \mathrm{mol}$ is likely a lower limit. Pyykkö's MP2 optimization of the $\left[\mathrm{ClCu}^{\mathrm{I}} \mathrm{PH}_{3}\right]_{2}$ dimer found an interaction potential of $-3.07 \mathrm{kcal} / \mathrm{mol} .^{22}$ Although Pyykkö's value is the BSSE-corrected dimerization energy at the MP2 level, rather than the difference between the HF and MP2 energies, a useful comparison can still be made. There is a total of nine possible intertrimer $\mathrm{Cu}-\mathrm{Cu}$ pairs, six in the range 3.628-3.979 $\AA$ and three in the range $4.832-5.191 \AA$. Since cuprophilicity is expected to die off rapidly as a function of distance (approximate $r^{-6}$ dependence), we assume the most significant contributions to overall cuprophilicity will be from the six closest contacts. Thus, counting the six closest $\mathrm{Cu}-\mathrm{Cu}$ intertrimer pairs, the cuprophilic stabilization is roughly equivalent to $-3 \mathrm{kcal} / \mathrm{mol}$ per pair.

A comparison of the ROHF and LMP2 results shows that the dimer of trimers is bound by cuprophilicity rather than electrostatic attraction in its singlet ground state. The soft translational potential energy surface (PES) for these systems ${ }^{1}$ is consistent with the weakness of metallophilic interactions and, thus, further strengthens the case for a substantial contribution to intertrimer bonding by cuprophilicity in the trimeric copper pyrazolate systems. It is amazing that the calculated average energy of each cuprophilic bond in $\left\{[\mathrm{Cu}(\mathrm{Pz})]_{3}\right\}_{2}$ is similar to that in the simple dimeric model $\left[\mathrm{ClCu}^{\mathrm{I}} \mathrm{PH}_{3}\right]_{2}$, despite the much longer $\mathrm{Cu} \cdots \mathrm{Cu}$ separations observed in the former (average $3.8 \AA$; vide supra) than in the latter staggered dimer (3.137 $\AA$ ). Furthermore, the total cuprophilic stabilization of $-18.1 \mathrm{kcal} /$ mol for $\left\{[\mathrm{Cu}(\mathrm{Pz})]_{3}\right\}_{2}$ is drastically greater than the estimate given by Poblet and Bénard of $-6 \mathrm{kcal} / \mathrm{mol}$ for the analogous $\left\{[\mathrm{CuL}]_{3}\right\}_{2}$ model with $\mathrm{L}=2$-[3(5)-pyrazolyl]pyridine. ${ }^{11,23} \mathrm{We}$ attribute these to a rather significant cooperativity of the cuprophilic bonding in $\left\{[\mathrm{Cu}(\mathrm{Pz})]_{3}\right\}_{2}$. Precedents of cooperativity in metallophilic systems have been reported for simple $\left[\mathrm{CuCl}_{2}\right]^{-},{ }^{24}$ $\mathrm{Hg}_{n}$ linear clusters, ${ }^{25}\left[\mathrm{Au}(\mathrm{CN})_{2}{ }^{-}\right]_{n}$ and $\left[\mathrm{Au}(\mathrm{CN})_{2}{ }^{-}\right]_{n}$ oligomeric complexes, ${ }^{26}$ and gold thiolate catenane systems. ${ }^{8}$

Excimeric Bonding in the $\mathbf{T}_{\mathbf{1}}$ Excited State. The geometries of chair and staggered conformations of the $\left\{[\mathrm{Cu}(\mathrm{Pz})]_{3}\right\}_{2}$ model were optimized using B3LYP/CSDZ* for both the lowest triplet excited state $\left(\mathrm{T}_{1}\right)$ responsible for phosphorescence and the singlet ground state $\left(\mathrm{S}_{0}\right)$. Figure 2 shows the frontier orbitals and optimized geometries for both $\mathrm{S}_{0}$ and $\mathrm{T}_{1}$ of the $\mathrm{C}_{i}$ staggered $\left\{[\mathrm{Cu}(\mathrm{Pz})]_{3}\right\}_{2}$ model, which gave lower energy than the chair in the $\mathrm{S}_{0}$ state. There are two doubly degenerate, highest occupied Kohn-Sham orbitals (HOKSOs) and a nondegenerate, lowest unoccupied Kohn-Sham orbital (LUKSO) for the $\mathrm{S}_{0}$ ground state (Figure 2). In the phosphorescent $\mathrm{T}_{1}$ state, on the other hand, the singly occupied Kohn-Sham orbitals (SOKSOs) are nondegenerate. Consistent with the singlet LUKSO, the upper 


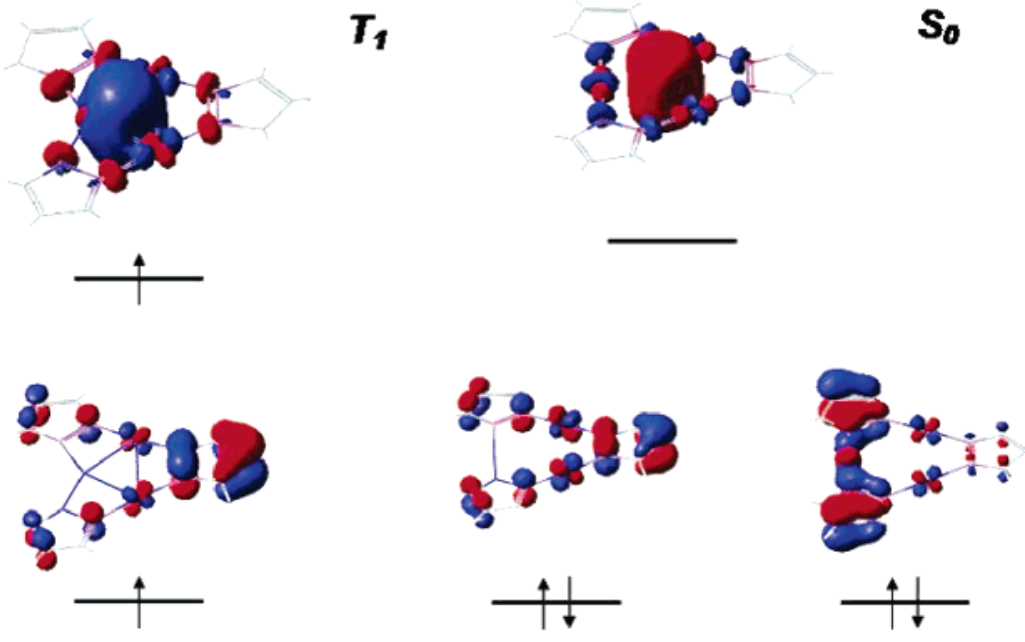

Figure 3. Contours of the frontier orbitals for the optimized $S_{0}$ and $T_{1}$ states of $[\mathrm{Cu}(\mathrm{Pz})]_{3}$.

TABLE 1: B3LYP/CSDZ* Optimized Intratrimer $\mathrm{Cu}-\mathrm{Cu}$ Distances for $\left\{[\mathbf{C u}(\mathbf{P z})]_{3}\right\}_{2}$ and $[\mathrm{Cu}(\mathbf{P z})]_{3}$ Models

\begin{tabular}{|c|c|c|c|c|c|}
\hline \multirow[b]{2}{*}{ model } & \multicolumn{4}{|c|}{ bond length $(\AA)$} & \multirow[b]{2}{*}{$\mathrm{T}_{1} \mathrm{symm}^{l}$} \\
\hline & & $\mathrm{T}_{1}$ & & $\mathrm{~S}_{0}$ & \\
\hline$\left\{[\mathrm{Cu}(\mathrm{Pz})]_{3}\right\}_{2}$, Chair & 3.373 & 3.163 & 3.075 & 3.319 & $\mathrm{C}_{i}$ \\
\hline$\left\{[\mathrm{Cu}(\mathrm{Pz})]_{3}\right\}_{2}$, Staggered & 3.222 & 3.222 & 2.978 & 3.308 & $\mathrm{C}_{i}$ \\
\hline $\multirow[t]{2}{*}{[\mathrm{Cu}(\mathrm{Pz})]_{3}}_{2}$, Staggered $^{a}$ & 3.283 & 3.123 & 3.019 & not found & $\mathrm{C}_{1}$ \\
\hline & 3.237 & 3.143 & 3.085 & & \\
\hline$[\mathrm{Cu}(\mathrm{Pz})]_{3}$ & 3.165 & 2.489 & 2.489 & 3.329 & $C_{2 v}$ \\
\hline
\end{tabular}

${ }^{a}$ Two sets of bond lengths are given, because symmetry did not constrain the $[\mathrm{Cu}(\mathrm{Pz})]_{3}$ units to the same dimensions. ${ }^{b}$ The $\mathrm{T}_{1}$ symmetry listed is the overall symmetry of the dimer of trimer.

SOKSO of $\mathrm{T}_{1}$ shows increased intertrimer bonding. Upon absorption of a photon, an electron from the nonbonding HOKSO is promoted to the LUKSO; we have confirmed that the LUKSO of $\mathrm{S}_{0}$ corresponds to the upper SOKSO of the nonoptimized $\mathrm{T}_{1}$ Franck-Condon excited state populated by the vertical electronic excitation transition (see Figure S1 in the Supporting Information). Since the LUKSO of the $\mathrm{S}_{0}$ state of $\left\{[\mathrm{Cu}(\mathrm{Pz})]_{3}\right\}_{2}$ has an intertrimer $\mathrm{Cu} \cdots \mathrm{Cu}$ bonding character, a contraction of the separation between the trimer units is expected and is, indeed, observed, as shown in the calculated structure of the $\mathrm{T}_{1}$ state upon which the contours of the SOKSOs are plotted in Figure 2. The planar distance (Figure 1b) exhibits a huge contraction, from $3.22 \AA$ in $S_{0}$ to $2.50 \AA$ in $T_{1}$ of $\left\{[\mathrm{Cu}(\mathrm{Pz})]_{3}\right\}_{2}$ ! Even with the decreased planar distance, the $\mathrm{Cu}_{3}$ cores of each monomer-of-trimer unit remain in parallel planes. In contrast, the pyrazolate ligands "ruffle" out of the plane described by the metal triangles for the triplet excited state.

Since the HOKSO of the $\mathrm{S}_{0}$ ground state of $\left\{[\mathrm{Cu}(\mathrm{Pz})]_{3}\right\}_{2}$ is doubly degenerate (Figure 2), the vertical excitation process is expected to attain Jahn-Teller instability within $D_{3 h}$. To lower the degeneracy, the $D_{3 h}$ symmetry (an equilateral triangle) of the $\mathrm{Cu}_{3}$ core can be reduced to $C_{2 v}$ (an isosceles triangle) or $C_{s}$ (a scalene triangle). ${ }^{27}$ In the $\mathrm{S}_{0}$ form, both units within the dimer of trimer have $D_{3 h}$ symmetry individually, so all intratrimer $\mathrm{Cu}-$ $\mathrm{Cu}$ bond lengths are equal. The $\mathrm{Cu}-\mathrm{Cu}$ bond lengths in the optimized $\mathrm{T}_{1}$ form of the $\left\{[\mathrm{Cu}(\mathrm{Pz})]_{3}\right\}_{2}$ species studied are detailed in Table 1, which also shows the bond lengths in the corresponding optimized $\mathrm{S}_{0}$ form for comparison. To better understand the effect of dimerization of $[\mathrm{Cu}(\mathrm{Pz})]_{3}$ units, Table 1 and Figure 3 show the results for an isolated $[\mathrm{Cu}(\mathrm{Pz})]_{3}$ monomer of trimer, which is also subject to photoinduced JahnTeller distortion.
Not all the models show the same Jahn-Teller distortion. The isolated monomer-of-trimer triplet exciton (Figure 3) has two of the bonds shortened to $2.489 \AA$ (Table 1), suggesting bona fide covalent $\mathrm{Cu}-\mathrm{Cu}$ bonds. This is considerably more than the contraction of the third bond to $3.165 \AA$. Thus, the $\mathrm{T}_{1}$ structure of isolated $[\mathrm{Cu}(\mathrm{Pz})]_{3}$ represents an isosceles triangle with two short sides and a long side (Table 1). On the other hand, the staggered symmetric structure of $\left\{[\mathrm{Cu}(\mathrm{Pz})]_{3}\right\}_{2}$ is calculated to undergo a photoinduced Jahn-Teller distortion to a $C_{2 v}$ symmetry for each trimer by shortening one bond much more than the other two, forming a long-long-short isosceles. The chair and nonsymmetric staggered structures show distortions to $C_{s}$ geometries for each trimer, forming scalene triangles.

Figures 4-6 show the calculated optimized structures of the three $\left\{[\mathrm{Cu}(\mathrm{Pz})]_{3}\right\}_{2}$ conformations represented in Table 1. Note that the $\mathrm{T}_{1}$ state of each model has the shortest $\mathrm{Cu}-\mathrm{Cu}$ distance as an intertrimer as opposed to an intratrimer interaction. All $\mathrm{S}_{0}$ models undergo molecular rearrangement upon photoexcitation, amounting for increased clustering of the $\mathrm{Cu}_{6}$ unit in the $T_{1}$ state. In all cases, the spin density for the triplet states is located primarily on the copper atoms and is not limited to two $\mathrm{Cu}$ atoms, suggesting that cooperativity is also valid for excimeric $\mathrm{Cu}-\mathrm{Cu}$ bonding. Although the $\mathrm{Cu}-\mathrm{Cu}$ bonding is enhanced in the $T_{1}$ state, the situation herein is different from that in a simple $*\left[\mathrm{Cu}^{+}\right]_{2}$ excimer, such as that encountered by Zink and co-workers in doped $\beta$-alumina solids. ${ }^{28}$ Although the latter excimer can be described by a conventional two-center/ two-electron bond, the data herein for $\left\{[\mathrm{Cu}(\mathrm{Pz})]_{3}\right\}_{2}$ and even $[\mathrm{Cu}(\mathrm{Pz})]_{3}$ clearly indicate delocalized excimeric bonding across multiple $\mathrm{Cu}$ centers. Delocalized $\mathrm{M}-\mathrm{M}$ excimeric bonding has been suggested upon one-photon absorption in other systems containing more than two adjacent transition metal atoms with a closed-shell ground state, such as $\mathrm{Hg}_{n}$ atomic clusters, ${ }^{25}$ as well as clusters of other ligand-containing complexes. ${ }^{29-31}$

It is interesting to note that the greatest intratrimer $\mathrm{Cu}-\mathrm{Cu}$ contraction in the photoexcited dimer-of-trimers is only $\sim 10 \%$, whereas the greatest contraction for an isolated monomer of trimer is roughly $25 \%$. This underscores that the excimeric bonding is primarily an intertrimer $\mathrm{Cu}-\mathrm{Cu}$ bonding effect in the $\mathrm{T}_{1}$ excited state of $\left\{[\mathrm{Cu}(\mathrm{Pz})]_{3}\right\}_{2}$ species (Figures 2 and $4-6$ ). In the absence of intertrimer effects (e.g., in systems that can be described as monomer-of-trimer crystallographically or perhaps in higher excited states than $T_{1}$ in dimers of trimers in which the excimeric bonding is intratrimer), one would expect that the geometric perturbation should behave more similarly to isolated monomers of trimers (Figure 3 and Table 1). In the 


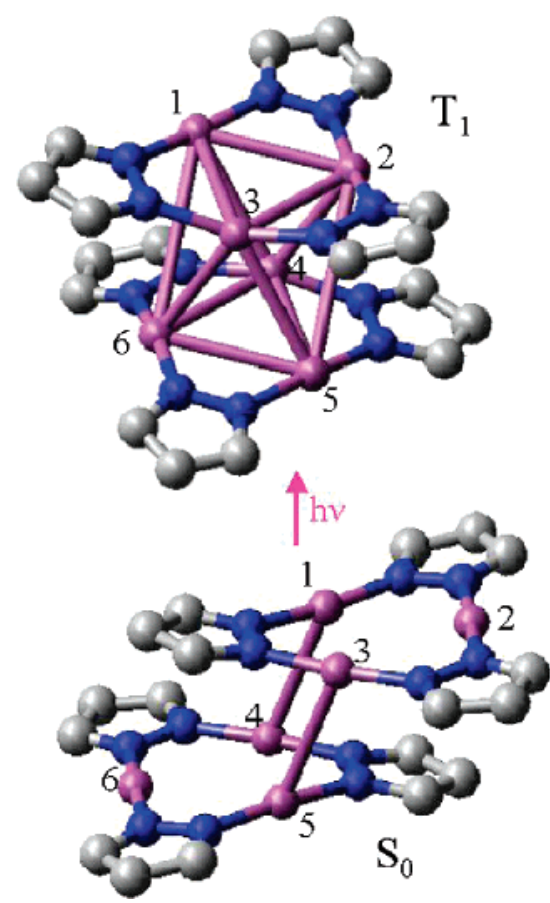

Figure 4. Optimized geometries of the $\mathrm{S}_{0}$ and $\mathrm{T}_{1}$ states of the chair conformation of $\left\{[\mathrm{Cu}(\mathrm{Pz})]_{3}\right\}_{2}$. $\mathrm{Cu}-\mathrm{Cu}$ distances $(\AA), \mathrm{S}_{0}: 1-2=5-6$ $=3.315,2-3=4-6=3.325,1-3=4-5=3.316,1-4=3-5=$ $3.231 ; \mathrm{T}_{1}: 1-2=5-6=3.373,2-3=4-6=3.075,1-3=4-5=$ $3.163,1-4=3-5=3.273,2-4=3-6=2.885,1-6=2-5=$ $4.383,3-4=2.813$ (shortest intertrimer contact). Average $\mathrm{Cu}-\mathrm{N}$, $\mathrm{C}-\mathrm{N}$, and $\mathrm{C}-\mathrm{C}$ distances $(\AA): \mathrm{S}_{0}, 1.904,1.347,1.395 ; \mathrm{T}_{1}, 1.949,1.348$, 1.396 .

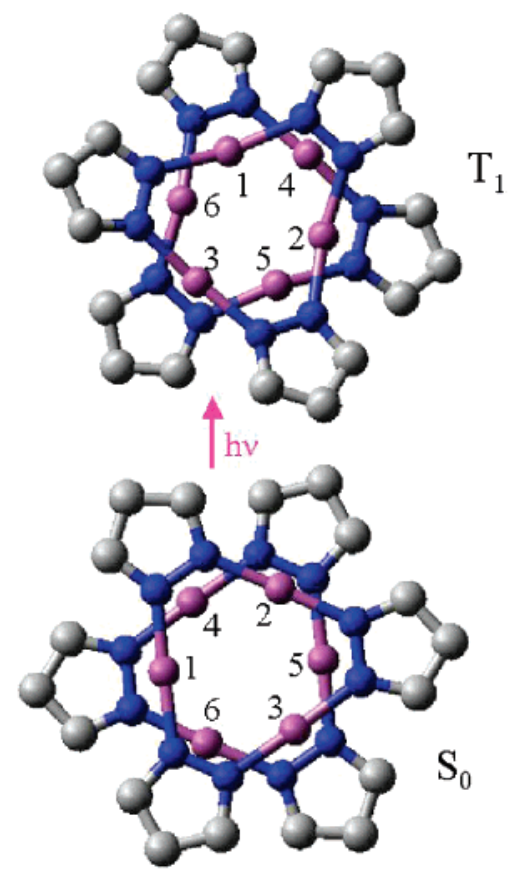

Figure 5. Optimized geometries of the $\mathrm{S}_{0}$ and $\mathrm{T}_{1}$ states of the staggered conformation of $\left\{[\mathrm{Cu}(\mathrm{Pz})]_{3}\right\}_{2}$. $\mathrm{Cu}-\mathrm{Cu}$ distances $(\AA), \mathrm{S}_{0}: 1-2=5-6$ $=3.317,2-3=4-6=3.297,1-3=4-5=3.310,1-4=3-5=$ $3.628,2-4=3-6=3.878,1-6=2-5=3.762 ; \mathrm{T}_{1}: 1-2=5-6=$ $2.978,2-3=4-6=3.222,1-3=4-5=3.222,1-4=3-5=$ $3.447,2-4=3-6=3.447,1-6=2-5=2.692$ (shortest intertrimer contact). Average $\mathrm{Cu}-\mathrm{N}, \mathrm{C}-\mathrm{N}$, and $\mathrm{C}-\mathrm{C}$ distances $(\AA)$ : $\mathrm{S}_{0}, 1.899$, $1.346,1.395 ; \mathrm{T}_{1}, 1.947,1.347,1.396$.

lowest energy staggered $C_{1}$ conformation of the $\mathrm{T}_{1}$ structure of $\left\{[\mathrm{Cu}(\mathrm{Pz})]_{3}\right\}_{2}$, Figure 6, the electronic energy is $3.35 \mathrm{eV}$ higher

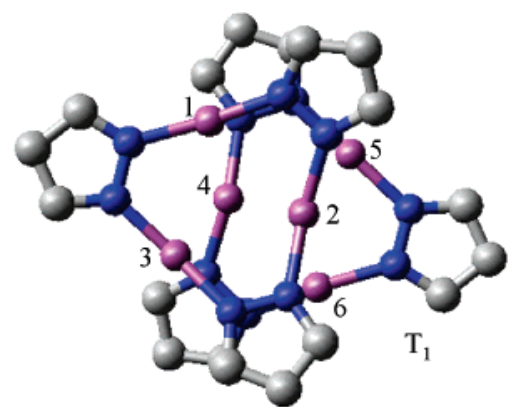

Figure 6. Optimized geometry of the $T_{1}$ state of the nonsymmetric staggered conformation of $\left\{[\mathrm{Cu}(\mathrm{Pz})]_{3}\right\}_{2} \cdot \mathrm{Cu}-\mathrm{Cu}$ distances $(\AA): 1-2$ $=3.085,4-5=3.123,1-3=3.237,4-6=3.019,2-3=3.143$, $5-6=3.283,1-4=2.875,3-4=2.812,2-5=2.812,2-6=2.809$ (shortest intertrimer contact), $2-4=2.931$. Average $\mathrm{Cu}-\mathrm{N}, \mathrm{C}-\mathrm{N}$, and $\mathrm{C}-\mathrm{C}$ distances $(\AA): 1.952,1.348,1.396$.

TABLE 2: Metrics $^{a}$ for B3LYP/CSDZ*-Optimized Geometries of $\left\{[\mathbf{M}(\mathbf{P z})]_{3}\right\}_{2}$

\begin{tabular}{ccccc}
\hline & \multicolumn{4}{c}{ distance $(\AA)$} \\
\cline { 2 - 5 } model & planar & horizontal & centroid & av intra-M-M \\
\hline $\mathrm{S}_{0},\left\{[\mathrm{Cu}(\mathrm{Pz})]_{3}\right\}_{2}$ & 3.224 & 0.280 & 3.236 & 3.308 \\
$\mathrm{~T}_{1},\left\{[\mathrm{Cu}(\mathrm{Pz})]_{3}\right\}_{2}$ & 2.497 & 0.900 & 2.654 & 3.141 \\
$\mathrm{~S}_{0},\left\{[\mathrm{Ag}(\mathrm{Pz})]_{3}\right\}_{2}$ & 3.223 & 0.708 & 3.300 & 3.572 \\
$\mathrm{~T}_{1},\left\{[\mathrm{Ag}(\mathrm{Pz})]_{3}\right\}_{2}$ & 2.743 & 1.052 & 2.938 & 3.289 \\
$\mathrm{~S}_{0},\left\{[\mathrm{Au}(\mathrm{Pz})]_{3}\right\}_{2}$ & 3.595 & 0.480 & 3.627 & 3.560 \\
$\mathrm{~T}_{1},\left\{[\mathrm{Au}(\mathrm{Pz})]_{3}\right\}_{2}$ & 2.840 & 2.987 & 4.122 & 3.376
\end{tabular}

${ }^{a}$ See Figure 1 for a description of the various metrics.

than the electronic energy of the ground-state singlet. The chair $\left(C_{i}\right)$ conformation gives a similar value $(3.39 \mathrm{eV})$. For comparison, the singlet - triplet splitting for the $[\mathrm{Cu}(\mathrm{Pz})]_{3}$ model is $3.48 \mathrm{eV}$. The transfer of an electron from the nonbonding HOKSO to the bonding LUKSO thus causes a large inter-ring contraction upon excitation to the lowest triplet state (Figure 6). A relatively small intraring contraction of $0.17 \AA$ (5\%) in the $\mathrm{Cu}-\mathrm{Cu}$ distances is calculated. This is dwarfed, however, by the $0.73 \AA(23 \%)$ decrease in inter-ring planar separation (Table 2). For comparison, a recent time-resolved X-ray diffraction experiment reported a contraction of the interplanar separation by $0.65 \AA$ (from $3.952(1)$ to $3.33(1) \AA$ ) for $\{[\mathrm{Cu}$ $\left.\left.\left(3,5-\left(\mathrm{CF}_{3}\right)_{2} \mathrm{Pz}\right)\right]_{3}\right\}_{2}$, whereas the intratrimer $\mathrm{Cu}-\mathrm{Cu}$ separations had negligible contraction. ${ }^{12}$ Given the additional steric bulk contributed by the $\mathrm{CF}_{3}$ substituents on the pyrazolate ring, the experimental photocrystallographic results are in excellent agreement with the theoretical analysis presented here.

Role of the Coinage Metal in Excited-State Distortions. Pyrazolate trimers of the entire coinage metal series display interesting chemical and photophysical properties, ${ }^{1}$ and thus, a computational study of possible excited-state distortions in $\left\{[\mathrm{Ag}(\mathrm{Pz})]_{3}\right\}_{2}$ and $\left\{[\mathrm{Au}(\mathrm{Pz})]_{3}\right\}_{2}$ was initiated. Table 2 gives the salient features of the geometries of $\left\{[\mathrm{M}(\mathrm{Pz})]_{3}\right\}_{2}(\mathrm{M}=\mathrm{Cu}, \mathrm{Ag}$, $\mathrm{Au}$ ) in both the $\mathrm{S}_{0}$ and $\mathrm{T}_{1}$ states. The computed geometries of the $S_{0}$ and $T_{1}$ states of the Ag and Au models are provided in the Supporting Information. All of these structures are stationary points located using B3LYP/CSDZ* methods starting from a staggered conformation; this conformation was selected because it represents the lowest-energy dimer-of-trimer $S_{0}$ form of $\left\{[\mathrm{Cu}(\mathrm{Pz})]_{3}\right\}_{2}$ and was, thus, assumed to be the same for the $\mathrm{Ag}$ and $\mathrm{Au}$ analogues. DFT calculations indicate the potential energy surface for the translation between the staggered conformation and the chair conformation is very soft (quantified by the horizontal misalignment, Figure 1c), and thus, there are minimal relevant differences between the optimized structures produced from different starting geometries. The rotation angle (Figure 

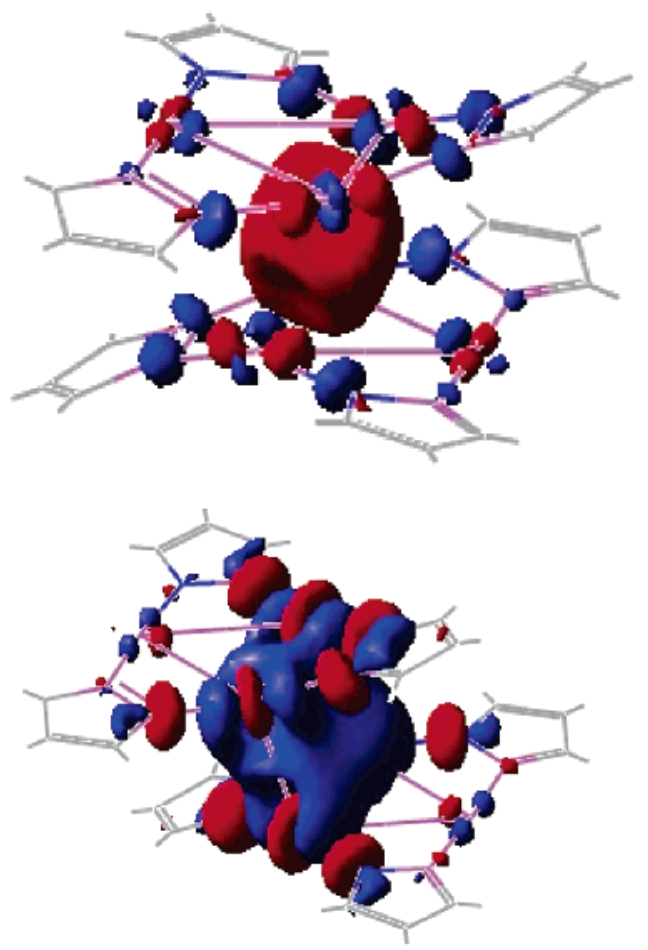

Figure 7. The higher SOKSO of the optimized $\mathrm{T}_{1}$ state of $\left\{[\mathrm{Ag}(\mathrm{Pz})]_{3}\right\}_{2}$ (top) and $\left\{[\mathrm{Au}(\mathrm{Pz})]_{3}\right\}_{2}$ (bottom).

TABLE 3: Experimental ${ }^{a}$ Structural Data for Coinage Metal Pyrazolate Trimers

\begin{tabular}{|c|c|c|c|c|c|c|}
\hline \multirow[b]{2}{*}{ metal } & \multicolumn{3}{|c|}{$\begin{array}{c}\text { intratrimer } \mathrm{M} \cdots \mathrm{M} \text { distance } \\
(\AA)\end{array}$} & \multicolumn{3}{|c|}{$\begin{array}{c}\text { intertrimer plane separation } \\
(\AA)\end{array}$} \\
\hline & av & $\min$. & $\max$ & av & $\min$ & $\max$ \\
\hline $\mathrm{Cu}$ & 3.24 & 3.16 & 3.41 & 3.82 & 3.70 & 4.14 \\
\hline $\mathrm{Ag}$ & 3.43 & 3.30 & 3.49 & N/A & N/A & N/A \\
\hline $\mathrm{Au}$ & 3.36 & 3.26 & 3.43 & 4.12 & 3.49 & 4.85 \\
\hline
\end{tabular}

${ }^{a}$ See ref 13 .

1d) between the monomers of trimers is always within $3^{\circ}$ of the staggered conformation according to these DFT calculations.

The search reported herein of the $\mathrm{CSD}^{13}$ shows that calculated intertrimer and intratrimer $\mathrm{M} \cdots \mathrm{M}$ distances are comparable with known coinage metal-pyrazolate complexes. Thirty coinage metal pyrazolate trimers, with differing pyrazolate substituents, were located to measure intratrimer distances $(6 \mathrm{Cu}, 2 \mathrm{Ag}, 22$ $\mathrm{Au}$ ), and 17 structures were located to measure intertrimer distances (4 $\mathrm{Cu}, 13 \mathrm{Au})$. A summary of the experimental structural data is given in Table 3. Comparing the calculated geometries for the singlet structures of $\left\{[\mathrm{M}(\mathrm{Pz})]_{3}\right\}_{2}$ in Table 2 with the experimental data (Table 3) shows the calculated intertrimer and intratrimer $\mathrm{M} \cdots \mathrm{M}$ distances are well in line with what is expected for these systems.

The calculated horizontal distance (Figure 1c) in the singlet state (Table 2) follows the same order as the van der Waals radii: ${ }^{32} \mathrm{Cu}(1.40 \AA)<\mathrm{Au}(1.66 \AA)<\mathrm{Ag}(1.72 \AA)$. This is also the same trend as that displayed by the intratrimer $\mathrm{M} \cdots \mathrm{M}$ bond lengths for the different metals according to our CSD search (Table 3). However, the trend is broken in the triplet state of $\left\{[\mathrm{M}(\mathrm{Pz})]_{3}\right\}_{2}$, for which the horizontal distances are $\mathrm{Cu}(0.9 \AA)$ $\approx \mathrm{Ag}(1.0 \AA) \ll \mathrm{Au}(3.0 \AA)$. Examination of the upper SOKSO for $\left\{[\mathrm{Cu}(\mathrm{Pz})]_{3}\right\}_{2}$ (Figure 2) and its Ag congener (Figure 7) indicates bonding in the triplet excited state that is distributed over all six metal ions. However, the upper SOKSO for $\{[\mathrm{Au}-$ $\left.(\mathrm{Pz})]_{3}\right\}_{2}$ (Figure 7) shows significant bonding between two $\mathrm{Au}-$
TABLE 4: DFT Calculated Photophysical Parameters for Coinage Metal Pyrazolate Systems

\begin{tabular}{lccc}
\hline \multicolumn{1}{c}{ complex } & $\begin{array}{c}\lambda_{\text {exc }} \\
(\mathrm{nm})\end{array}$ & $\begin{array}{c}\lambda_{\text {em }} \\
(\mathrm{nm})\end{array}$ & $\begin{array}{c}\text { Stokes' shift } \\
\left(10^{3} \mathrm{~cm}^{-1}\right)\end{array}$ \\
\hline$[\mathrm{Cu}(\mathrm{Pz})]_{3}$ & 256 & 401 & 14.1 \\
$\left\{[\mathrm{Cu}(\mathrm{Pz})]_{3}\right\}_{2}$ & 292 & 450 & 16.7 \\
{$[\mathrm{Ag}(\mathrm{Pz})]_{3}$} & 262 & 452 & 16.0 \\
$\left\{[\mathrm{Ag}(\mathrm{Pz})]_{3}\right\}_{2}$ & 328 & 455 & 8.4 \\
{$[\mathrm{Au}(\mathrm{Pz})]_{3}$} & 237 & 321 & 11.0 \\
$\left\{[\mathrm{Au}(\mathrm{Pz})]_{3}\right\}_{2}$ & 240 & 349 & 13.0 \\
{$\left[\mathrm{Cu}\left(3-\left(\mathrm{CF}_{3}\right) \mathrm{Pz}\right)\right]_{3}$} & 277 & 403 & 11.3 \\
$\left\{\left[\mathrm{Cu}\left(3-\left(\mathrm{CF}_{3}\right) \mathrm{Pz}\right)\right]_{3}\right\}_{2}$ & 268 & 428 & 13.9 \\
{$\left[\mathrm{Cu}\left(3,5-\left(\mathrm{CF}_{3}\right)_{2} \mathrm{Pz}\right)\right]_{3}$} & $a$ & 498 & $a$ \\
{$\left[\mathrm{Ag}\left(3,5-\left(\mathrm{CF}_{3}\right)_{2} \mathrm{Pz}\right)\right]_{3}$} & 248 & 475 & 19.3 \\
{$\left[\mathrm{Au}\left(3,5-\left(\mathrm{CF}_{3}\right)_{2} \mathrm{Pz}\right)\right]_{3}$} & 320 & 574 & 13.9 \\
${ }^{a} \mathrm{The}$ vertical excitation energy for this complex could not be \\
computed due to SCF convergence failure.
\end{tabular}

$\mathrm{Au}$ pairs rather than the delocalized interaction found in the $\mathrm{Cu}$ and $\mathrm{Ag}$ derivatives.

The CSD data (Table 3) show a large variation in intertrimer distances and a smaller variation in the intratrimer distances. The intratrimer $\mathrm{M}-\mathrm{M}$ bond distances vary by $0.25,0.19$, and $0.17 \AA$ for $\mathrm{Cu}, \mathrm{Ag}$, and $\mathrm{Au}$, respectively. The intratrimer metalmetal distances can be compared to the intertrimer variation of $0.44 \AA$ in the copper-pyrazolate trimer compounds and a massive $1.36 \AA$ in the gold compounds (Table 3 ). Given the structural diversity of the substituted pyrazolate ligands considered, this seems to be a good indication of the practicability of tuning the intertrimer distance using different ligands and, hence, the resultant emission wavelengths for the coinage metal pyrazolates (vide infra).

The most compelling finding derived from these computations on the triplet emissive state is the observation that contraction of the intertrimer $\mathrm{M} \cdots \mathrm{M}$ spacing in $\left\{[\mathrm{M}(\mathrm{Pz})]_{3}\right\}_{2}$ upon excitation is much greater than the contraction of the intratrimer $\mathrm{M} \cdots \mathrm{M}$ distances. The intertrimer contraction in the planar separation is 23,15 , and $21 \%$ for $\mathrm{Cu}, \mathrm{Ag}$, and $\mathrm{Au}$, respectively, giving an average contraction of $20 \%$ (Table 2). Within each monomerof-trimer subunit, the contraction of the intratrimer $\mathrm{M} \cdots \mathrm{M}$ bond distance is $5 \%$ for $\mathrm{Cu}$ and $\mathrm{Au}$ and $8 \%$ for $\mathrm{Ag}$, giving an average of only $6 \%$.

Calculated Photophysical Properties. One of the interesting experimental features of these pyrazolate complexes is their large Stokes' shifts, ${ }^{1}$ which implies significant excited-state geometric distortion. DFT calculations above verified the geometric distortion, and so in this section, we now report the calculated photophysical properties. Table 4 summarizes the $\mathrm{S}_{0} \rightarrow \mathrm{T}_{1}$ excitation $\left(\lambda_{\text {exc }}\right)$ and $T_{1} \rightarrow S_{0}$ phosphorescent emission $\left(\lambda_{\text {em }}\right)$ wavelengths calculated for the vertical transitions.

Several observations are of interest with respect to the calculated photophysical properties. First, the calculated Stokes' shifts of the coinage metal pyrazolate monomers of trimers and dimers of trimers lie in the range of $8-20 \times 10^{3} \mathrm{~cm}^{-1}$, similar to experimental values ${ }^{1,2,4}$ and consistent with the drastic enhancement in the $\mathrm{M}-\mathrm{M}$ bonding upon photon absorption for all monomer-of-trimer and dimer-of-trimer models, as discussed above. Second, among the unsubstituted $[\mathrm{M}(\mathrm{Pz})]_{3}$ theoretical models, the $\mathrm{Cu}$ and $\mathrm{Ag}$ complexes are calculated to exhibit much more significant red shifts upon dimerization, as compared to the analogous gold complex in terms of both the excitation and phosphorescence energy; the latter energy shifts to the visible region for the $\mathrm{Cu}$ and $\mathrm{Ag}$ dimers of trimers but remains in the UV region for $\left\{[\mathrm{Au}(\mathrm{Pz})]_{3}\right\}_{2}$. It is somewhat surprising that dimerization of $[\mathrm{Ag}(\mathrm{Pz})]_{3}$ does not significantly affect the emission energy, whereas the excitation energy red-shifts by 
$7680 \mathrm{~cm}^{-1}$. Both the excitation and emission energies are computed to be red-shifted significantly (by 4820 and 2720 $\mathrm{cm}^{-1}$, respectively) upon dimerization of the unsubstituted copper complex). Third and more importantly, computed photophysical parameters are provided for the practical models with substituted pyrazolates, thus permitting direct comparison with experiment and facilitating the often-difficult assignment of the excitation and emission bands seen for the experimental systems. ${ }^{1,2,4}$ The visible emissions in all $\mathrm{CF}_{3}$-substituted models computed (Table 4) are consistent with experimental studies that gave rise to multiple visible phosphorescence bands attributed to different excited states of monomer-of-trimer and dimer-of-trimer excitons. ${ }^{1,2}$ Basis set and method limitations, however, preclude a quantitative comparison with the experimental systems. For example, we find that the calculated ${ }^{1} \mathrm{~S} \rightarrow$ ${ }^{3} \mathrm{D}$ vertical excitation energies of the atomic systems $\mathrm{Cu}^{+}, \mathrm{Ag}^{+}$, and $\mathrm{Au}^{+}$using B3LYP/CSDZ* are higher than the stateweighted experimental ${ }^{33}$ values by 6390,4690 , and $5520 \mathrm{~cm}^{-1}$, respectively. Similar deviations are found in the literature for the ${ }^{1} \mathrm{~S} \rightarrow{ }^{3} \mathrm{P}$ excitation energy of the mercury atom when similar methodologies are used. ${ }^{25}$ Nevertheless, useful trends can be extracted from the computed photophysical energies herein. For example, among the monomer-of-trimers models in Table 4, the $\mathrm{Cu}$ and $\mathrm{Au}$ complexes are computed to undergo red shifts in the excitation energies with $\mathrm{CF}_{3}$ substitution by 1600 and $10420 \mathrm{~cm}^{-1}$ for $\left[\mathrm{Cu}\left(3-\left(\mathrm{CF}_{3}\right) \mathrm{Pz}\right)\right]_{3}$ and $\left[\mathrm{Au}\left(3,5-\left(\mathrm{CF}_{3}\right)_{2} \mathrm{Pz}\right)\right]_{3}$, respectively, relative to the corresponding unsubstituted analogues. The red shift upon $\mathrm{CF}_{3}$-substitution of the $\mathrm{Au}$ trimer is rather substantial, even from a qualitative perspective. Contrary to the $\mathrm{Cu}$ and $\mathrm{Au}$ models, the vertical excitation wavelength is computed to undergo a substantial blue shift by $9930 \mathrm{~cm}^{-1}$ for $\left[\mathrm{Ag}\left(3,5-\left(\mathrm{CF}_{3}\right)_{2} \mathrm{Pz}\right)\right]_{3}$, in comparison with $[\mathrm{Ag}(\mathrm{Pz})]_{3}$. With these trends, it appears that, overall, the $\mathrm{Cu}$ and $\mathrm{Au}$ complexes behave similarly, whereas the trends are reversed for Ag complexes. However, the phosphorescence energy upon disubstitution in $\left[\mathrm{M}\left(3,5-\left(\mathrm{CF}_{3}\right)_{2} \mathrm{Pz}\right]_{3}\right.$ models $(\mathrm{M}=\mathrm{Cu}, \mathrm{Ag}, \mathrm{Au})$ is computed to be red-shifted with respect to the corresponding unsubstituted analogues. Even then, the $\mathrm{Cu}$ and $\mathrm{Au}$ complexes are far more red-shifted (by 4860 and $13730 \mathrm{~cm}^{-1}$, respectively) than the Ag complex $\left(1070 \mathrm{~cm}^{-1}\right)$. These results are consistent with the available experimental data for $\left[\mathrm{M}\left(3,5-\left(\mathrm{CF}_{3}\right)_{2} \mathrm{Pz}\right]_{3}\right.$ crystalline solids, in which the lowest-energy phosphorescence energy is significantly higher for the $\mathrm{Ag}$ trimer, as compared to the $\mathrm{Cu}$ and $\mathrm{Au}$ analogues, ${ }^{1}$ especially given the aforementioned result that the unsubstituted $\mathrm{Ag}$ trimer is computed to exhibit much lower sensitivity to dimerization than the $\mathrm{Cu}$ and $\mathrm{Au}$ analogues.

\section{Summary and Conclusions}

A comprehensive computational study of the structural and spectral properties of the ground and phosphorescent excited states of trimeric coinage metal pyrazolates is presented. Several important conclusions have been reached as a result of this research. First, cuprophilic stabilization in the singlet ground state of $\left\{[\mathrm{Cu}(\mathrm{Pz})]_{3}\right\}_{2}$ is $18.1 \mathrm{kcal} / \mathrm{mol}$, overcoming electrostatic repulsion between the like-charged $\mathrm{d}^{10}$ metal centers. This cuprophilic interaction is, however, still relatively weak, leading to a soft PES. The large variation in intertrimer separations found in ground state coinage metal pyrazolates supports a relatively weak, hence tunable, intertrimer interaction. Second, the emissive triplet excited state of $\left\{[\mathrm{M}(\mathrm{Pz})]_{3}\right\}_{2}$ is predicted by density functional calculations to show major geometric perturbations due to a Jahn-Teller distortion and excimeric $\mathrm{M}-\mathrm{M}$ bonding. Specifically, population of the lowest unoccupied Kohn-Sham orbitals enhances $\mathrm{M} \cdots \mathrm{M}$ bonding, contracting both the intra- trimer and intertrimer distances. The intertrimer $\mathrm{M} \cdots \mathrm{M}$ distances contract much more than intratrimer contraction (20\% versus $6 \%$ ), whereas the percent contraction does not change significantly with the coinage metal used. Third, intertrimer M $\cdots \mathrm{M}$ contractions in the $\mathrm{T}_{1}$ state are roughly equal for the copper and gold complexes (20\%) and slightly less for the silver congener $(15 \%)$. Furthermore, the geometry of the phosphorescent triplet excited state of $\left\{[\mathrm{Au}(\mathrm{Pz})]_{3}\right\}_{2}$ indicates that the $\mathrm{M} \cdots \mathrm{M}$ bonding is more localized than in the copper and silver analogues. Fourth, the calculated photophysical properties indicate less sensitivity in the excitation wavelength $\left(\lambda_{\text {exc }}(\mathrm{av})\right.$ $\sim 270 \pm 30 \mathrm{~nm}$ ) but more variability in the phosphorescence wavelength $\left(\lambda_{\mathrm{em}}(\mathrm{av}) \sim 440 \pm 70 \mathrm{~nm}\right)$ with coinage metal and pyrazolate substituent modification, which is consistent with experimental spectroscopic data. Furthermore, very large Stokes' shifts are calculated $\left(\sim 15000 \mathrm{~cm}^{-1}\right)$, similar to those reported for the relevant experimental models.

Taken together, the observations deduced from these calculations point to the great potential of tuning the emission properties of coinage metal pyrazolate trimers through judicious choice of the metal and pyrazolate substituents and allow the prediction of the excited-state structures. Although the latter can now be determined experimentally by time-resolved diffraction, ${ }^{12}$ the limited range and accessibility of such experimental investigations render it essential that computational methods be utilized for such purposes, especially given the excellent agreement of the calculated ground- and excited-state structures herein with the experimental ones, even for such large dimer-of-trimer systems. Currently, experiments and computations are underway in our labs to further explore these implications for the design of improved light-emitting devices.

Acknowledgment. Support for CASCaM through the U.S. Department of Education is gratefully acknowledged. T.R.C. acknowledges the Office of Basic Energy Sciences, U.S. Department of Energy, for support of this research through Grant No. DE-FG02-03ER15387. T.G. acknowledges the University of North Texas Graduate School for a fellowship. M.A.O. acknowledges financial support of his contribution by the Robert A. Welch Foundation (Grant B-1542) and the National Science Foundation (CAREER Award CHE-0349313). H.V.R.D. thanks the National Science Foundation (CHE-0314666) and the Robert A. Welch Foundation (Grant Y-1289) for financial support.

Supporting Information Available: Further computational results for the optimized structures of models discussed in the manuscripts (PDF). This material is available free of charge via the Internet at http://pubs.acs.org.

\section{References and Notes}

(1) Omary, M. A.; Rawashdeh-Omary, M. A.; Gonser, M. W. A.; Elbjeirami, O.; Grimes, T.; Cundari, T. R.; Diyabalanage, H, V. K.; Palehepitiya Gamage, C. S.; Dias, H. V. R. Inorg. Chem. 2005, 44, 8200.

(2) (a) Dias, H. V. R.; Diyabalanage, H. V. K.; Rawashdeh-Omary, M. A.; Franzman, M. A.; Omary, M. A. J. Am. Chem. Soc. 2003, 125 , 12072. (b) Dias, H. V. R.; Diyabalanage, H. V. K.; Eldabaja, M. G.; Elbjeirami, O.; Rawashdeh-Omary, M. A.; Omary, M. A. J. Am. Chem. Soc. 2005, 127, 7489. (c) Dias, H. V. R.; Polach, S. A.; Wang, Z. J. Fluor. Chem. 2000, 103, 163. (d) Dias, H. V. R.; Diyabalanage, H. V. K. Polyhedron 2006, in press.

(3) Burini, A.; Bravi, R.; Fackler, J. P., Jr.; Galassi, R.; Grant, T. A.; Omary, M. A.; Pietroni, B. R.; Staples, R. J. Inorg. Chem. 2000, 39, 3158.

(4) Yang, G.; Raptis, R. G. Inorg. Chem. 2003, 42, 261.

(5) For reviews, see: (a) Burini, A.; Mohamed, A. A.; Fackler, J. P., Jr. Comments Inorg. Chem. 2003, 24, 253. (b) Omary, M. A.; Mohamed, A. A.; Rawashdeh-Omary, M. A.; Fackler, J. P., Jr. Coord. Chem. Rev. 2005, 249, 1372. 
(6) (a) Rawashdeh-Omary, M. A.; Omary, M. A.; Fackler, J. P., Jr.; Galassi, R.; Pietroni, B. R.; Burini, A. J. Am. Chem. Soc. 2001, 123, 9689. (b) Burini, A.; Fackler, J. P., Jr.; Galassi, R.; Grant, T. A.; Omary, M. A.; Rawashdeh-Omary, M. A.; Pietroni, B. R.; Staples, R. J. J. Am. Chem. Soc. 2000, 122, 11264.

(7) For reviews, see: (a) Pyykkö, P. Chem. Rev. 1997, 97, 597. (b) Pyykkö, P. Angew. Chem., Int. Ed. 2004, 43, 4412.

(8) Mendizabal, F.; Pyykkö, P.; Runeberg, N. Chem. Phys. Lett. 2003, 370,733 .

(9) (a) Merz, K. M., Jr.; Hoffmann, R. Inorg. Chem. 1988, 27, 2120.

(b) Jiang, Y.; Alvarez, S.; Hoffmann, R. Inorg. Chem. 1985, 24, 749. (c)

Mehrotra, P. K.; Hoffmann, R. Inorg. Chem. 1978, 17, 2187. (d) Dedieu,

A.; Hoffmann, R. J. Am. Chem. Soc. 1978, 100, 2074

(10) Carvajal, M. A.; Alvarez, S.; Novoa, J. J. Chem.-Eur. J. 2004, 10, 2117.

(11) Poblet, J. M.; Bénard, M. Chem. Commun. 1998, 1179.

(12) Vorontsov, I. I.; Kovalevsky, A. Y.; Chen, Y.-S.; Graber, T.; Gembicky, M.; Novozhilova, I. V.; Omary, M. A.; Coppens, P. Phys. Rev. Lett. 2005, 94, 193003.

(13) Allen, F. H. Acta Crystallogr., Sect. B: Struct. Sci. 2002, 58, 380.

(14) Jaguar, version 5.5; Schrodinger, Inc.: Portland, OR (www.schrodinger.com).

(15) Cundari, T. R.; Stevens, W. J.; Sommerer, S. O. J. Chem. Phys. 1993, 98,5555

(16) Sæb $\varnothing$, S.; Pulay, P. Theor. Chim. Acta 1986, 69, 357.

(17) Boys, S.; Bernardi, F. Mol. Phys. 1970, 90, 553

(18) Sæbø, S.; Tong, W. J. Chem. Phys. 1993, 98, 2170

(19) Ehlert, M. K.; Rettig, S. J.; Storr, A.; Thompson, R. C.; Trotter, J. Can. J. Chem. 1990, 68, 1444.

(20) Fujisawa, K.; Ishikawa, Y.; Miyashita, Y.; Okamoto, K.-I. Chem. Lett. 2004, 33, 66 .

(21) (a) Singh, K.; Long, J. R.; Stavropoulos, P. J. Am. Chem. Soc. 1997 119, 2942. (b) Singh, K.; Long, J. R.; Stavropoulos, P. Inorg. Chem. 1998 37, 1073. 1451.

(22) Pyykkö, P.; Runeberg, N.; Mendizabal, F. Chem.-Eur. J. 1997, 3 ,

(23) The estimation in ref 11 was not based on quantum mechanical calculations for the dimer-of-trimer model. It was made simply by assigning a stabilization value for each intertrimer distance in the crystal structure of $\left\{[\mathrm{CuL}]_{3}\right\}_{2}$ on the basis of half the stabilization value inferred from Pyykkö's $\mathrm{PES}$ for $\left[\mathrm{ClCu}^{\mathrm{I}} \mathrm{PH}_{3}\right]_{2}$

(24) Kohn, R. D.; Seifert, G.; Pan, Z.; Mahon, M. F.; Kociok-Kohn, G. Angew. Chem., Int. Ed. 2003, 42, 793.

(25) Omary, M. A.; Sinha, P.; Bagus, P. S.; Wilson, A. K. J. Phys. Chem A 2005, 109, 690

(26) See, for example, Table 5 in: Omary, M. A.; Webb, T. R.; Assefa, Z.; Shankle, G. E.; Patterson. H. H. Inorg. Chem. 1998, 37, 1380. See also Tables 3-4 and Figure 9 in: Rawashdeh-Omary, M. A.; Omary, M. A.; Patterson, H. H. J. Am. Chem. Soc. 2000, 122, 10371.

(27) Burdett, J. Molecular Shapes; John Wiley \& Sons: New York, 1980; p 173.

(28) (a) Hollingsworth, G.; Barrie, J. D.; Dunn, B.; Zink, J. I. J. Am. Chem. Soc. 1988, 110, 6569. (b) Barrie, J. D.; Dunn, B.; Holilingsworth, G.; Zink, J. I. J. Phys. Chem. 1989, 93, 3958.

(29) (a) Clodfelter, S. A.; Doede, T. M.; Brennan, B. A.; Nagle, J. K.; Bender, D. P.; Turner, W. A.; LaPunzia, P. M. J. Am. Chem. Soc. 1994, 116, 11379. (b) Nagle, J. K.; Brennan, B. A. J. Am. Chem. Soc. 1988, 110, 5931.

(30) (a) White-Morris, R. L.; Olmstead, M. M.; Jiang, F.; Tinti, D. S.; Balch, A. L. J. Am. Chem. Soc. 2002, 124, 2327. (b) White-Morris, R. L.; Olmstead, M. M.; Jiang, F.; Balch, A. L. Inorg. Chem. 2002, 41, 2313.

(31) (a) Omary, M. A.; Patterson, H. H. J. Am. Chem. Soc. 1998, 120, 7696. (b) Rawashdeh, M. A.; Omary, M. A.; Patterson, H. H.; Fackler, J. P., Jr. J. Am. Chem. Soc. 2001, 123, 11237.

(32) Winter, M. WebElements (Professional Edition). http:// www.webelements.com/(accessed May 2005).

(33) Moore, C. E. Atomic Energy Levels; Nat. Bur. Stand.: Washington, 1958; Vol. III. 